\title{
On the Contribution of Philosophical and Geoscientific Inquiry to Geoeth- ics (qua Applied Ethics)
}

\author{
THOMAS PÖLZLER \\ Institute of Philosophy, University of Graz, Austria \\ thomas.poelzler@uni-graz.at
}

\begin{abstract}
This paper is about the methodology of geoethics qua applied ethics. In particular, I investigate the contributions of philosophical and geoscientific inquiry. My investigation is based on a general model of geoethical research. For each stage of this model I explain the expected contribution of "the philosopher" and "the geoscientist" (assuming that they are different persons). These general considerations are illustrated by the example of a particular geoethical research question that is currently addressed in the Austrian Academy of Sciences project EE-Con. It turns out that geoethical research is a complex multi-step process that is highly contingent on philosophical assumptions. In advancing this research it will be helpful for philosophers and geoscientists to work together more closely than they have done so far.
\end{abstract}

\section{INTRODUCTION}

$\mathrm{G}$ eoethics addresses questions at the intersection of geoscience and philosophy. One kind of geoethical questions, among many others, can be understood as a sub-category of what philosophers refer to as "applied ethics" (Beauchamp, 2003). Researchers in this area investigate controversial geoscience-related moral issues that people face in their everyday lives or that are relevant to political decision-making. In what follows I will be exclusively concerned with this particular area of geoethical research.

Geoethics is a growing field of research (see, e.g., Bobrowsky et al., 2017; Hourdequin, 2015; Peppoloni and Di Capua, 2012; Peppoloni et al., 2017; Philips 2012; Wyss and Peppoloni, 2015). Compared to bioethics, neuroethics and other areas of applied ethics, there has so far been little reflection on its methodology. In this paper I attempt to advance geoethics qua applied ethics by addressing a particularly important methodological issue, namely the contribution of philosophical and geoscientific inquiry. I hence conform to recent suggestions according to which philosophers engaged in geoethics are to "offer a synopsis of how the various disciplines relate within a given problem" (Frodeman, 2003: 20), and are "to step into a $[\ldots]$ kind of collaboration that investigates relationships between the disciplines $[\ldots]^{\prime \prime}$ (Stefanovic, 2015: 21).

In clarifying the relation of philosophical and geoscientific inquiry in the above-mentioned area of geoethics I will refer to a general model of geoethical research in this area. For each stage of this model I will explain the expected contribution of "the philosopher" and "the geoscientist" (assuming that they are different persons). These general considerations will be illustrated by the example of a particular geoethical research question that is currently addressed in the Austrian Academy of Sciences project EE-Con (Ortner et al., 2017).

\section{DEVELOPING A GEOETHICAL RESEARCH QUESTION}

The first step in geoethical research is to develop appropriate research questions. Research questions in this area need to conform to the same general requirements as research questions in other areas. Most importantly, they must be feasible (in terms of the available methods, time, money, etc.), interesting (in ad- 
vancing knowledge or being practically relevant), and novel (in going beyond past findings) (see Hulley et al., 2007).

Philosophers will often be able to contribute substantially to developing geoethical research questions. Given their background in moral theory, they can identify potential moral issues reliably, and can formulate interesting and precise questions about these issues. At the same time, geoscientists are indispensable to this process as well. They can yield information about relevant facts, the results of related geoscientific studies, the expected feasibility and range of outcomes of future studies, etc.

In EE-Con geographers found that many residents of three Austrian alpine valleys expect that despite their proper awareness of increasing natural hazards they will be able to continue to live in these areas. This expectation is likely to have shaped the residents' plans. So if at some point in the future the state of Austria decided to relocate these residents, it would thereby make it difficult or impossible for them to realize these plans. One important ethical question raised by this potential frustration of the residents' plans - the question that we address in EE-Con - looks as follows: Is the harm caused by the frustration of residents' expectation morally significant, i.e., does it ground a moral claim against relocation or for compensation?

\section{ADOPTING A GENERAL APPROACH TO APPLIED ETHICS}

Applied ethical questions can be approached in three main ways: top-down, bottom-up, and intermediate (see Beauchamp, 2003; Hourdequin, 2015).

According to the top-down approach (e.g., Singer, 1979), answers to such questions must be deduced from moral principles (i.e., general moral statements that apply to all or particular kinds of cases) and the relevant facts. On the most abstract level, for example, the question of where to build a new landfill might be addressed as follows: "We ought to act in such a way as to maximize overall happiness (utilitarian moral principle). Building the landfill at place $X$ will maximize overall happiness (rele- vant fact). Ergo, the landfill ought to be built at place X."

According to the bottom-up approach (e.g., Toulmin and Jonsen, 1988), applied ethical questions are to be answered by paying close attention to the specific details of cases rather than by deduction from principles. Proponents of casuistry, for example, argue that moral judgements about particular cases are to be justified by comparing these cases to similar cases, in particular to less controversial ones (e.g., comparing the planned landfill with a landfill at place $\mathrm{Z}$ that caused severe groundwater pollution).

The intermediate approach combines both topdown and bottom-up features. According to its most prominent variant (e.g., Daniels, 1979), one's general moral principles and considered moral judgements about particular cases are justified to the extent that they cohere. This state of "reflective equilibrium" can be approached by continued mutual adjustments at both levels. For example, if the above utilitarian principle conflicts with one's considered moral judgement about where to build the new landfill one may refine/reject either or both this principle and one's judgement.

Whether geoethical questions are approached in a top-down, bottom-up or intermediate manner is the most important determinant of this research's methodology. Here I will proceed under the assumption that justifying moral judgements in geoethics at some point and in some sense requires deductions from moral principles. This assumption is not only consistent with the top-down approach, but also with the reflective equilibrium model (proponents of this model just insist that principles are open to refinement or rejection) and even with some bottom-up approaches (see Beauchamp, 2003: 9-10). My considerations will hence have very broad appeal.

Concerning the relation of philosophical and geoscientific inquiry, the adoption and potential adjustment of any of the above approaches requires considerable philosophical expertise. Researchers need to fully understand how moral judgements are justified according to their preferred approach. But geoscientists are essential to this general methodological discussion as well. Most importantly, they will stress 
and contribute to implementing a problemsolving - as opposed to primarily theoretical - perspective.

\section{DEVELOPING, ADOPTING AND/OR SPECIFYING A RELEVANT MORAL PRINCIPLE}

Given that geoethical research requires deductions from moral principles, the next step in this research consists in developing, adopting and/or specifying such principles.

Some moral principles are claimed to apply only to particular kinds of cases. Geoscientists are necessary in determining whether the case at issue falls under the scope of such principles. For example, does a particular case of groundwater pollution only raise intragenerational or also intergenerational justice issues? In many other respects, developing, adopting and/or specifying appropriate moral principles is primarily the responsibility of philosophers (since they are familiar with existing moral principles, arguments for and against these principles, and methods of specifying principles).

In EE-Con we adopted two principles about the moral significance of expectations that were developed by Meyer and Sanklecha (2011, 2014). First, in order for an expectation to be morally significant it must be epistemically sound, i.e., based on good reasons, as specified by a plausible philosophical theory of justification (e.g., when a person for no good reason expects that she will be given $€ 50$ million by the state of Austria this expectation's frustration clearly does not ground a claim to compensation, apology, etc.). And second, the expectation must also be just, i.e., meet substantive constraints of pure procedural justice (e.g., when a person for good reasons expects that she will not be caught cheating on her income taxes this expectation's frustration does not ground a claim to compensation, apology, etc. either).

In order to be applicable to controversial cases moral principles must often be specified. Drawing on Meyer and Sanklecha's work (2011, 2014), we specified the epistemic soundness and justice principles roughly as follows. A person's expectation is epistemically sound if (E1) the person has reason to believe that the state has ensured the expectation's fulfillment in the past and will not discontinue to ensure this fulfillment in the future, or (E2) the person has reason to believe that the state expresses that it will ensure the expectation's fulfillment. A person's expectation is just if and only if (J1) the expectation is not based on impartial considerations, and (J2) the expectation is consistent with her general views about justice.

\section{DERIVING A TESTABLE GEOSCIENTIFIC HYPOTHESIS FROM THE MORAL PRINCIPLE}

From their preferred moral principle(s) geoethicists must next derive testable geoscientific hypotheses. This will often be a two-step process. First, one must identify the kind(s) of facts about the particular case at issue that, according to the principle, are morally relevant (this step requires detailed knowledge of the principle, and is thus mainly within the domain of philosophy). And second, one must develop testable geoscientific hypotheses that allow for conclusions about the facts identified in step one (this step requires detailed knowledge about the particular case and about geoscientific methods, and is thus mainly within the domain of geoscience).

Recall the above principle according to which expectations can only be morally significant if they can be inferred from states' past behavior (E1) or states' expressions (E2). From this principle it can be inferred that determining the moral significance of residents' expectation that they will be able to continue to live in our study areas requires investigating whether this expectation is grounded in past behavior or expressions by the state of Austria (Step 1). These questions may then be explored by testing various kinds of geoscientific hypotheses; for example, that help from disaster relief funds has not decreased over the last decades or that the state still issues building permits for our study areas (Step 2).

\section{IDENTIFYING THE GEOSCIENTIFIC METHODS MOST APPROPRIATE FOR TESTING THE HYPOTHESIS}

Depending on the moral principle and the particular case, the geoscientific hypotheses at issue may be such that testing them requires 
studies in both or either physical geoscience and human geoscience. Many of the following considerations apply to studies of both kinds. My primary object of investigation, however, will be geoethical research that is based on studies in human geoscience (such as in EECon).

Human geoscientists use a variety of different methods. Abstracting from any practical constraints, the method(s) that geoethicists should adopt in testing their geoscientific hypotheses is that (are those) method(s) that can be expected to provide the strongest evidence with regard to the hypothesis. In the EE-Con project, for example, we investigated residents' beliefs, emotions and behaviors regarding natural hazards and their potential resettlement both by questionnaires (to obtain more objective, unbiased data) and by structured interviews (to gain deeper insight into the underlying causes of these beliefs, emotions and behaviors).

Determining which method(s) can be expected to provide the strongest evidence with regard to the geoscientific hypothesis at issue requires both theoretical knowledge about geoscientific methods and experience in employing them. Thus, it will typically fall in the domain of the geoscientist.

\section{DEVELOPING A SPECIFIC RESEARCH DESIGN}

Based on their general choice of methods, researchers in geoethics next need to develop (a) specific design(s) for their geoscientific study (studies). Questionnaire studies, for example, raise the following issues: What is the required sample size? How ought one to formulate instructions, scenarios, questions, and answer choices? Should one use open-ended or closeended questions (or both)?

Obviously, the geoscientific studies employed in geoethical research should have as much internal and external validity as possible. Ensuring this goal is again mainly the responsibility of the geoscientist (who is familiar with the relevant methods and with potential problems in employing them). In addition, philosophical expertise may be helpful in designing certain kinds of geoscientific studies in geoethics too. This is especially true for studies that attempt to test subjects' philosophical views. Such studies will only be internally valid if the philosophical concepts figuring in their instructions, scenarios, questions, and answer choices are used properly - and philosophers are typically more familiar with these concepts.

Recall J1, the first condition of EE-Con's justice principle (according to which a person's expectation can only be morally significant if it is consistent with her general views about justice). In order to test whether residents' expectation to be able to continue to live in our study areas fulfills this condition one's study must include answer choices that, if residents chose them, would indicate that their expectation is not consistent with their general views about justice. A view that might be relevant here is libertarianism, which claims that states' only legitimate function is to protect citizens from criminal behavior (e.g., Nozick, 1974). Suppose a resident's study responses indicate that $\mathrm{s} /$ he is drawn to libertarianism. As this general view about justice in some sense conflicts with the expectation that the state will offer protection, aid and relief with regard to natural hazards, such a finding would support that the resident's expectation lacks in moral significance.

\section{CONDUCTING THE GEOSCIENTIFIC STUDY}

With a complete research design at hand, researchers in geoethics can finally go on to test their morally relevant geoscientific hypothesis. Several issues in the philosophy of science might be relevant to this task, e.g., the theorydependence and value-ladenness of scientific observations. Apart from these general issues, however, testing the morally relevant geoscientific hypothesis is obviously the task of the geoscientist. Hence, I will not explain this step any further.

\section{ASSESSING THE STUDY'S IMPLICATIONS FOR THE GEOSCIENTIFIC HYPOTHESIS}

In order to be able to support or undermine a particular hypothesis the data resulting from one's geoscientific studies must be interpreted. Given their training and experience, geoscien- 
tists are better suited to performing this task than philosophers. They identify trends in the data more rapidly and reliably, are more aware of common cognitive biases, etc. Again, however, the philosopher's conceptual knowledge may prove helpful as well - in particular with studies that address subjects' philosophical views.

In the study that led to EE-Con's geoethical research question, for example, many subjects in both the questionnaires and interviews strongly agreed that "[t]he society is responsible for the protection against natural hazards". At first sight this finding might be thought to support the study's hypothesis that most residents expect the society to protect them against natural hazards. But this interpretation would be flawed. To expect that an agent performs an action means to believe that the agent will perform that action (Meyer and Sanklecha, 2014: 2). By saying that an agent is responsible for performing an action, however, we express that the agent ought to perform rather than that s/he actually will perform that action - and it is possible and common to believe that agents ought to perform actions that they actually will not perform. Hence, the finding that residents of our study areas agreed that the society is responsible for protecting them against natural hazards does not by itself entail that they expect the society to do so.

\section{ASSESSING THE STUDY'S IMPLICATIONS FOR THE GEOETHICAL RESEARCH QUESTION}

Given that all previous tasks were performed successfully, the interpretation of one's geoscientific data will either support or undermine one's geoscientific hypothesis. The final step in geoethical research qua applied ethical research is to assess the implications of this result for one's geoethical research question.

One important determinant of this assessment is one's general approach to applied ethics. Suppose one's moral principle(s) (e.g., EECon's justice principle) and geoscientific findings (e.g., our interview data) entail a moral judgement that conflicts with one's considered judgement about the case at issue (e.g., that residents' expectation that they will be able to continue to live in our study areas is morally significant). On the top-down approach one would then have to give up one's considered moral judgement. The reflective equilibrium model, in contrast, also allows the rejection or refinement of the principle, and thus requires further philosophical (and perhaps geoscientific) research.

When one assumes more than one moral principle, answering geoethical research questions may also require weighing the judgements entailed by one principle against the judgements entailed by others. Moreover, issues of feasibility may have to be considered as well. Suppose, for example, it turned out that residents' above expectation grounds a claim to not being resettled. Accounting for this expectation (i.e., protecting residents from increasing natural hazards) may be costly - so costly that the state of Austria may become unable to (fully) meet other morally significant expectations of its citizens (such as students' expectations to receive scholarships). To arrive at an all-thingsconsidered judgement, answering EE-Con's geoethical research question would thus require weighing this expectation against other morally significant expectations.

In any case, as the above considerations demonstrate, assessing one's study's implications for the geoethical research question is primarily the task of the philosopher (as s/he is more familiar with approaches to applied ethics, the weighing of principle, the implications of infeasibility, etc.). The geoscientist will mainly be important when it comes to translating one's findings into concrete practical solutions.

\section{CONCLUSION}

This paper focused on geoethics qua applied ethics. In particular, I asked about the contributions of philosophical and geoscientific inquiry to geoethics in this sense. It turned out that even on a simplified and idealized representation geoethical research is a complex multi-step process that is highly contingent on philosophical assumptions. Moreover, there is no clearcut division of labor between philosophers and geoscientists. At various stages geoethical research requires intensive exchange and collaboration. In advancing geoethics it will thus be 
helpful for philosophers and geoscientists to work together more closely than they have done so far.

\section{ACKNOWLEDGEMENTS}

This work was funded by the Austrian Academy of Sciences (OeAW) project Economic and Ethical Consequences of Natural Hazards in Alpine Valleys (EECon). For helpful comments I would like to thank Florian Ortner, Giuseppe di Capua, and the two reviewers of this paper.

\section{REFERENCES}

Beauchamp, T. L. (2003). The nature of applied ethics. In: Frey, R. G; Wellman, C. H. (eds.). A Companion to Applied Ethics. Malden: Blackwell, 1-16.

Bobrowsky P.; Cronin V.; Di Capua G.; Kieffer S.; Peppoloni S. (2017). The emerging field of geoethics. In: Gundersen, L. (ed.). Scientific Integrity and Ethics: With Applications to the Geosciences. American Geophysical Union: New York.

Daniels, N., (1979). Wide reflective equilibrium and theory acceptance in ethics. Journal of Philosophy 76 (5), 256-282.

Frodeman, R. (2003). Geo-logic: Breaking Ground between Philosophy and the Earth Sciences. Albany: State University of New York Press.

Hulley, S. B.; Cummings, S. R.; Browner, W. S.; Grady, D. G.; Newman, T. B. (2007). Designing Clinical Research. Philadelphia: Lippincott Williams \& Wilkins.

Hourdequin, M. (2015). Environmental Ethics: From Theory to Practice. London: Bloomsbury.

Jonsen, A.R.; Toulmin, S. (1998). The Abuse of Casuistry. Berkeley: University of California Press.

Meyer, L.; Sanklecha, P. (2011). Individual Expectations and Climate Change. Analyse \& Kritik 32 (2), 449-471.

Meyer, L.; Sanklecha, P. (2014). How legitimate expectations matter in climate justice. Politics, Philosophy \& Economics 13 (3), 369393.

Nozick, R. (1974): Anarchy, State, and Utopia. Basic Books: New York.

Ortner, F.; Pölzler, T.; Meyer, L.; Sass, O. (2017). Natural hazards and the normative signifi- cance of expectations in protecting alpine communities. In: EGU (ed.). Geophysical Research Abstracts: Abstracts of the European Geosciences Union General Assembly. Munich: Copernicus.

Peppoloni, S.; Di Capua, G. (eds.) (2012). Geoethics and geological culture. Reflections from the Geoitalia Conference 2011. Annals of Geophysics 55 (3).

Peppoloni S.; Di Capua G.; Bobrowsky P.T.; Cronin V.S. (2017). Geoethics at the heart of all geoscience. Annals of Geophysics (60), Fast Track 7.

Phillips, Jonathan (2012). Storytelling in Earth sciences: Eight basic plots. Earth-Science Reviews 115 (3), 153-162.

Peter Singer (1979). Practical Ethics. Cambridge: Cambridge University Press.

Stefanovic, I. L. (2015). Geoethics: Reenvisioning applied philosophy. In: Wyss, M.; Peppolini, S. (eds.): Geoethics: Ethical Challenges and Case Studies in Earth Sciences. Amsterdam: Elsevier.

Wyss, M.; Peppoloni, S. (eds.) (2015). Geoethics: Ethical Challenges and Case Studies in Earth Sciences. Amsterdam: Elsevier. 